\title{
Fitting the Nigeria Stock Market Return Series Using GARCH Models
}

\author{
U. Usman ${ }^{1}$, H. M. Auwal1 ${ }^{1}$ M. A. Abdulmuhyi ${ }^{2}$ \\ ${ }^{1}$ Department of Mathematics (Statistics Unit), Usmanu Danfodiyo University, Sokoto, Nigeria \\ ${ }^{2}$ Department of Accountancy, Federal Polytechnic, Bauchi, Nigeria \\ Email: *uusman07@gmail.com
}

How to cite this paper: Usman, U., Auwal, H.M. and Abdulmuhyi, M.A. (2017) Fitting the Nigeria Stock Market Return Series Using GARCH Models. Theoretical Economics Letters, 7, 2159-2176. https://doi.org/10.4236/tel.2017.77147

Received: April 25, 2017

Accepted: December 9, 2017

Published: December 14, 2017

Copyright (c) 2017 by authors and Scientific Research Publishing Inc. This work is licensed under the Creative Commons Attribution International License (CC BY 4.0).

http://creativecommons.org/licenses/by/4.0/

(c) (i) Open Access

\begin{abstract}
This study investigated the performance of eleven competing time series GARCH models for fitting the rate of returns data, monthly observations on the index returns series of the market over the period of January 1996 to December 2015 was used. From the results obtained from the Log Likelihood (Log L), Schwarzs Bayesian Criterion (SBC) and the Akaike Information Criterion (AIC) values it was found that the models identified was not the same for the two periods (Training and Testing period) that is for Training period were CGARCH $(1,1)$ and EGARCH $(1,1)$ while for Testing period were ARCH (1) and GARCH $(2,1)$. The two extreme classes of models are identified to represent the best and the worst groups respectively. The overall effect of this will tend to increase the volatility of the market returns. The paper therefore recommended that the Nigeria government should as a matter of urgency take appropriate positive measures through the security and exchange commission to regulate the market volatility so that the provided market index could be safely used as predictive index for measuring the performance of the firms and as a guide for investment purpose.
\end{abstract}

\section{Keywords}

GARCH Model, Returns, Fitting, Ranking

\section{Introduction}

The study employ different univariate specifications of GARCH type model for monthly observations on the index returns series. Furthermore, because of the sensitivity of global and regional economics models, there is more increasing attention in research in these areastime series GARCH models for fitting the rate of returns data. Studies involving stock market return, foreign exchange rates, 
inflation rates are wide. In addition, stock market exhibits changes in variance over time in such circumstances, that the assumption of constant variance (homoscedasticity) is inappropriate. The variability in the financial data could very well be due to the volatility of the financial market. More importantly, the extended financial market as well as globalization due to the markets is known to be sensitive to factors such as rum ours, political upheavals and changes in the government monetary and fiscal policies [1]. [2] Introduced the Autoregressive Conditional Heteroscedastic (ARCH) model process to cope with the changing variance. [2] Extended the Generalized Autoregressive Conditional Heteroscedastic (GARCH) model which has a more flexible lag structure because the error variance can be modeled by an Autoregressive Moving Average (ARMA) type process. Such a model can be effective in removing the excess kurtosis. There have been a great number of empirical applications of modeling the conditional variance (volatility) of financial time series by employing different specifications of these models and their many extensions. For example, [3], [4], [5], and [6], provide an extended methodological framework that can be applied to various problems in finance. The volatility models applied in this study include the ARCH (1), ARCH (2), GARCH $(1,1)$, GARCH $(1,2)$, GARCH $(2,1)$, EGARCH $(1,1)$, PARCH $(1,1)$, GRJGARCH $(1,1)$, CGARCH $(1,1)$ and GARCH-M $(1,1)$ and GARCH $(2,2)$. In these models, the volatility process is time varying and is modeled to be dependent upon both the past volatility and past innovations. These models have been used in many applications of stock return data, interest rate data, foreign exchanged etc. We focus upon one aspect of GARCH models, namely, their ability to deliver volatility. In other words, these models are useful not only for modeling the historical process of volatility but also in giving us multi-period a head forecasts. We evaluate the performance of these models in terms of their ability to give adequate forecasts. One traditional difficulty in constructing these tests is that the volatility process is in recently unobservable. We surmount this problem by using a proxy of monthly volatility calculated using daily data. Since our alternative measure of volatility is essentially model free and is estimated using higher frequency data, we have more faith in their liability of these volatility estimates. Various specifications for theme an equation and variance equation are entertained. We perform othin-sample and out-of-sample tests on these GARCH pecifications.

The objective of this study is to employ different univariate specifications of GARCH type model for monthly observations on the index returns series of the market over the period of January 1996 to December 2015 and to model stock returns volatility in Nigeria Stock Markets.

\section{Literature Review}

It has been a large amount of literature on modeling stock market return volatility in both developed and developing countries around the world. The volatility characteristics have been investigated using econometrics models. However, no 
single model is superior. The idea of using factor models with GARCH goes back to Engle, [7] who use the capital asset pricing model to show how the volatilities and fitted model between individual equities can be generated from the univariate GARCH variance of the stock market return. This model has been generalized by [8] to the case where the fitted model is time-varying. To avoid the need for a univariate GARCH parameterization and to keep the model as simple as possible, this "dynamic conditional fitted model" uses a GARCH $(1,1)$ model with the same parameters for all the elements of the fitted model. [9] Examined time-series features of stock returns and volatility in four of China's stock markets. They provided strong evidence of time-varying volatility and indicated volatility is highly persistent and predictable. By employing eleven competing time series models for fitting the rate of returns data to evaluate the performance of these models, [10] predict volatility of some stock markets returns. However, when asymmetric loss functions are applied ARCH-type models provide the best fitted model.

The univariate generalised autoregressive conditional heteroscedasticity (GARCH) models that were introduced [1] and [2] have been very successful for short and medium term volatility forecasting in financial markets. An alternative univariate GARCH models, were used in different financial markets. Many of these are being successfully applied to generating convergent term structure volatility forecasts, and in stochastic volatility models for option pricing and hedging. Various time series methods are employed by [11], including the simple GARCH model, the GARCH-in-Mean model and the exponential GARCH to investigate the Risk-Return Trade-off on the Romanian stock market. Results of the study confirm that E-GARCH is the best fitting model for the Bucharest Stock Exchange composite index volatility in terms of sample-fit. The Autoregressive Conditional Heteroscedastic (ARCH) model proposed by [1] and its extension, the Generalized Autoregressive Conditional Heteroscedastic (GARCH) model which has a more flexible lag structure because the error variance can be modeled by an Autoregressive Moving Average (ARMA) type process developed independently by [2], have been the first models introduced into the literature and have become very popular [12]. [10] Used both symmetric and asymmetric ARCH-type models to derive volatility expectations. The outcome showed that there has a positive effect of expected volatility on weekly and monthly stock returns of both Philippines and Thailand markets according to ARCH model. The result is not clear if using the other models such as GARCH, GJR-GARCH and EGARCH. [13] Demonstrates that the increases in variance of stock returns can explain much of the decline in stock prices. [14] Offers empirical evidence for a positive relation between a lagged volatility measure and future expected returns. For Asian stock markets return, [15] and [16] found that the conditional variance is an asymmetric function of past innovations. For emerging African markets, [17] investigate the market volatility using Nigeria and Kenya stock return series. Results of the exponential GARCH model indicate that asymmetric volatility found in the U.S. and other developed markets is also present in Nige- 
rian stock market (NSM), but Kenya shows evidence of significant and positive asymmetric volatility. Also, they show that while the Nairobi Stock market return series indicate negative and insignificant risk-premium parameters, the NSM returns series exhibit a significant and positive time-varying premium. [18] Studied the impacts of Inflation dynamics and global financial crises on stock market returns and volatility in Nigeria. The data sets on monthly All Shares Index Prices of NSE and consumers "price index (CPI)" cover the period of January, 1985 to December, 2010 were used. The GARCH $(1,1)$ model with multivariate regresses were adopted and the result shows that in the conditional mean equation; inflation exerts insignificant positive impact on stock market returns and during the global financial crises, inflation exerts significant negative effect on stock market returns. [19] Investigate the volatility of Naira/Dollar exchange rates in Nigeria using GARCH $(1,1)$, GJR-GARCH $(1,1)$, EGARCH $(1,1)$, APARCH $(1,1), \operatorname{IGARCH}(1,1)$ and TS-GARCH $(1,1)$ models. Using monthly data over the period January 1970 to December 2007, volatility persistence and asymmetric properties are investigated for the Nigerian foreign exchange. The results from all the models shows that volatility is persistent and the results from all the asymmetry models rejected the hypothesis of leverage effect. TSGARCH and APARCH models are found to be the best models. Several researchers such as [20], [21] and [22] had shown that models with a small lag like GARCH $(1,1)$ is sufficient to cope with the changing variance. Nevertheless, due to the high volatility of the rate of returns of the NSM, higher order lag models such as the GARCH $(1,2), \operatorname{GARCH}(2,1)$ and GARCH $(2,2)$. In all, the study shall compare the performance of eleven competing time series models for fitting the rate of returns data. The models are the ARCH (1), ARCH (2), GARCH $(1,1), \mathrm{GARCH}$ $(1,2)$, GARCH $(2,1)$, EGARCH $(1,1)$, PARCH $(1,1)$, GRJGARCH $(1,1)$, CGARCH $(1,1)$ and GARCH-M $(1,1)$ and GARCH $(2,2)$. [23], attempts to fit the generalized Autoregressive conditional Heteroscedastic (GARCH) model for All Share Index (ASI) of Nigerian Stock Market (NSM) returns. The data used in this paper are the daily All Share Index (ASI) of Nigerian stock market from January 2007 to December 2011 covering 1231 data points including business days and excluding public holidays. A research is made on various GARCH variants specified on the assumptions of stationarity and asymmetry. However, as [24] pointed out, it may not be reasonable to assume that the loading best or worst fit model is constant over time. We suggest finding the best and worst fit of the OGARCH model that allows for time-varying loadings.

\section{Data and Methods}

Autoregressive Conditional Heteroscedasticity (ARCH) and its Generalization (GARCH) models represent the main methodologies that have been applied in modeling stock market volatility in finance time series. These models can be effective in removing the excess kurtosis. In this research different univariate GARCH specifications are employed to model stock returns volatility in Nigeria Stock Market Returns the models are to be used for testing symmetric volatility. 


\subsection{Data Description}

The data used in this research work, is the monthly rate of returns of the (Nigeria Stock Market) (NSM), registered from January 1996 to December 2015. In the fourth quarter of 2006, political crisis which hit the Asian region had badly hurt the performance of most of the Oil Market in the world including the NSM (Nigeria Stock Market).

The data were divided in to two periods: Training Period from January 1996 to December 2006 and Testing Period from January 2007 to December 2015.

The monthly rate of returns $r_{i}$ of the NSM are calculated using the following formula:

$$
r_{t}=\log \left(\frac{I_{t}}{I_{t-1}}\right), t=1,2, \cdots, T
$$

where $I_{T}$ denotes the reading on the composite index at the close of $t^{\text {th }}$ trading day. As noted earlier, the rate of monthly returns of the NSM displays a changing variance over time. There are many ways to describe the changes in variance and one of them is by considering the Autoregressive Conditional Heteroscedasticity (ARCH) model.

\subsection{ARCH (P) Processes}

Suppose for now that $\varepsilon_{1}, \varepsilon_{2}, \cdots$ is Gaussian white noise with unit variance. Later we will allow the noise to be independent white noise with a possibly non normal distribution, such as, a standardized t-distribution. Then

$$
E\left(\varepsilon_{t} \mid \varepsilon_{t-1}, \cdots\right)=0
$$

and

$$
\operatorname{Var}\left(\varepsilon_{t} \mid \varepsilon_{t-1}, \cdots\right)=1
$$

Property (2) is called conditional homoskedasticity.

The process $a_{t}$ is an ARCH $(q)$ process under the model

$$
a_{t}=\sqrt{\omega+\alpha_{1} a_{t-1}^{2} \varepsilon_{t}}
$$

Equation (4) is a special case of (3) with fequal to 0 and $\sigma$ equal to $\sqrt{\omega+\alpha_{1} a_{t-1}^{2}}$. These research require that $\omega>0$ and $\alpha_{1} \geq 0$ so that $\alpha_{0}+\alpha_{1} a_{t-1}^{2}>0$. It is also required that $\alpha_{1}<1$ in order for $a_{t}$ to be stationary with a finite variance. Equation (4) can be written as

$$
a_{t}^{2}=\left(\omega+\alpha_{1} a_{t-1}^{2}\right) \varepsilon_{t}^{2}
$$

Which is very much like an $\operatorname{AR}(q)$ but in $a_{t}^{2}$, not $a_{t}$ and with multiplicative noise with a mean of 1 rather than additive noise with a mean of 0 .

\subsection{PARCH $(p, q)$ Model}

[25] Introduced the Power ARCH (PARCH) specification to deal with asymmetry. Unlike other GARCHN models, in this model, the standard deviation is modeled rather than the variance as in most of the GARCH-family. In Power 
ARCH an optional parameter can be added to account for asymmetry [26]. The model also offers one opportunity to estimate the power parameter instead of imposing to $\mathrm{n}$ the model [27]. The general power ARCH model specifies $\sigma_{t}$ as of the following form:

$$
\sigma_{t}^{\delta}=\omega+\beta_{1} \sigma_{t-1}^{\delta}+\alpha_{1}\left(\left|\varepsilon_{t-1}\right|-\gamma_{1} \varepsilon_{t-1}\right)^{\delta}
$$

where $\alpha_{1}$ and $\beta_{1}$ are the standard ARCH and GARCH parameters, $\gamma_{1}$ is the leverage parameter and $\delta$ is the parameter for the power term. When $\delta=2$ Equation (6) becomes a classic GARCH model that allows for leverage effects, and when $\delta=1$, the conditional standard deviation will be estimated.

\subsection{GARCH $(p, q)$ Models as ARMA $(p, q)$ Models}

The similarities seen in between GARCH and ARMA models are not a coincidence. If $a_{t}$ is a GARCH process, then $a_{t}^{2}$ is an ARMA process but with weak white noise, not i.i.d. white noise. To show this, we will start with the GARCH $(1,1)$ model, where $a_{t}=\sigma_{t}^{2} \varepsilon_{t}$. Here $\varepsilon_{t}$ is i.i.d. white noise and

$$
E_{t-1}\left(a_{t}^{2}\right)=\sigma_{t}^{2}=\omega+\alpha_{1} a_{t-1}^{2}+\beta_{1} \sigma_{t-1}^{2}
$$

where $e_{t-1}$ is the conditional expectation given the information set at time $t-1$. Define $\eta_{t}=a_{t}^{2}-\sigma_{t}^{2}$. Since $E_{t-1}\left(\eta_{t}\right)=E_{t-1}\left(a_{t}^{2}\right)-\sigma_{t}^{2}=0$, by $\eta_{t}$ is an uncorrelated process, that is, a weak white noise process. The conditional heteroskedasticity of $a_{t}$ is inherited by $\eta_{t}$ so $\eta_{t}$ is not i.i.d. white noise.

Simple algebra shows that

$$
\sigma_{t}^{2}=\omega+\left(\alpha_{1}+\beta_{1}\right) a_{t-1}^{2}-\beta_{1} \eta_{t-1}
$$

And therefore

$$
a_{t}^{2}=\sigma_{t}^{2}+\eta_{t}=\omega+\left(\alpha_{1}+\beta_{1}\right) a_{t-1}^{2}-\beta_{1} \eta_{t-1}+\eta_{t}
$$

Assume that $\alpha_{1}+\beta_{1}<1$. If $\mu=\omega /\left\{1-\left(\alpha_{1}+\beta_{1}\right)\right\}$, then

$$
a_{t}^{2}-\mu=\left(\alpha_{1}+\beta_{1}\right)\left(a_{t-1}^{2}-\mu\right)+\beta_{1} \eta_{t-1}+\eta_{t}
$$

From (9) one sees that $a_{t}^{2}$ is an ARMA $(1,1)$ process with mean $\mu$. Using the notation of the AR (1) coefficient is $\varphi_{1}=\alpha_{1}+\beta_{1}$ and the MA (1) coefficient is $\theta_{1}=-\beta_{1}$.

For the general case, assume that $\sigma_{t}$ follows so that

$$
\sigma_{t}^{2}=\omega+\sum_{i=1}^{p} \alpha_{i} a_{t-i}^{2}+\sum_{i=1}^{q} \beta_{i} \sigma_{t-i}^{2}
$$

Assume also that $p \leq q$-this assumption causes no loss of generality because, if $q>p$, then we can increase $p$ to equal $q$ by defining $\alpha_{i}=0$ for $i=p+1, \cdots, q$.

Define $\mu=\omega /\left\{1-\sum_{i=1}^{p}\left(\alpha_{i}+\beta_{i}\right)\right\}$. Straightforward algebra similar to the GARCH $(1,1)$ case shows that

$$
a_{t}^{2}-\mu=\sum_{i=1}^{p}\left(\alpha_{i}+\beta_{i}\right)\left(a_{t-1}^{2}-\mu\right)-\sum_{i=1}^{q} \beta_{i} \eta_{t-i}+\eta_{t}
$$

So that $a_{t}^{2}$ is an ARMA $(p, q)$ process with mean $\mu$. As a byproduct of these 
calculations, we obtain a necessary condition for $a_{t}$ to be stationary:

$$
\sum_{i=1}^{p}\left(\alpha_{i}+\beta_{i}\right)<1
$$

\subsection{EGARCH $(p, q)$ Model}

[4] Proposed a class of exponential GARCH or EGARCH models. In this model ht is defined by

$$
\operatorname{In}\left(h_{t}\right)=\omega+\sum_{i-1}^{q} \alpha_{i} g\left(e_{t-1}^{2}\right)+\sum_{j-1}^{p} \beta_{j} \operatorname{In}\left(h_{t-1}\right)
$$

where

$$
g\left(e_{t}\right)=\theta e_{t}+\gamma\left|e_{t}\right|-\gamma E\left|e_{t}\right|
$$

The coefficient of the second term in $g\left(e_{t}\right)$ is set to be $1(\gamma=1)$ in this formulation. Unlike the linear GARCH model there are no restrictions on the parameters to ensure non-negativity of the conditional variances.

\subsection{GARCH-M $(p, q)$ Model}

In the GARCH-in-Mean or GARCH-M model, the GARCH effects appear in the mean of the process, given by

$$
\varepsilon_{t}=\sqrt{h_{t} e_{t}}
$$

where $e_{t} \sim N(0,1)$ and $r_{t}=\mu+\delta \sqrt{h_{t}+\varepsilon_{t}}$ for the model with intercept and $r_{t}=\delta \sqrt{h_{t}+\varepsilon_{t}}$ for the non-intercept model. For the model GARCH $(p, q)$ specification, [5] suggested to adopt low orders for the lag lengths $p$ and $q$.

The GARCH $(p, q)$ is the most widely used GARCH process, so it is worthwhile to study it in some detail. If $a_{t}$ is $\operatorname{GARCH}(p, q)$, then as we have just seen, $a_{t}^{2}$ is $\operatorname{ARMA}(p, q)$.

$$
\rho_{a}^{2}(1)=\frac{\alpha_{1}\left(1-\alpha_{1} \beta_{1}-\beta_{1}^{2}\right)}{1-2 \alpha_{1} \beta_{1}-\beta_{1}^{2}}
$$

and

$$
\rho_{a}^{2}(k)=\left(\alpha_{1}+\beta_{1}\right)^{k-1} \rho_{a}^{2}(1), k \geq 2
$$

By (14), there are infinitely many values of $\left(\alpha_{1}, \beta_{1}\right)$ with the same value of $\rho_{a}^{2}(1)$. By (15), a higher value of $\alpha_{1}+\beta_{1}$ means a slower decay of $\rho_{a}^{2}$ after the first lag.

\subsection{The Component GARCH (CGARCH) Model}

It allows mean reversion to a varying level $\mu_{t}$

$$
\begin{gathered}
\sigma_{t}^{2}-m_{t}=\varpi+\alpha\left(u_{t-1}^{2}-\varpi\right)+\beta\left(\sigma_{t-1}^{2}-\varpi\right) \\
m_{t}=\omega+\rho\left(m_{t-1}-\omega\right)+\phi\left(u_{t-1}^{2}-\sigma_{t-1}^{2}\right)
\end{gathered}
$$

$\sigma_{t-1}^{2}$ is still the volatility, while $m_{t}$ takes the place of $\omega$ and is the time varying long-run volatility. The first equation describes the transitory component, $\sigma_{t}^{2}-m_{t}$ which converges to zero with powers of $(\alpha+\beta)$. The second equation 
describes the long run component $m_{t}$, which converges to $\omega$ with powers of $\rho$.

\subsection{GJR-GARCH $(p, q)$ Model}

[28] The GJR-GARCH, or just GJR, model of [28] allows the conditional variance to respond differently to the past negative and positive innovations. The GJR $(1,1)$ model maybe expressed as:

$$
\sigma_{t}^{2}=\omega+\alpha \varepsilon_{t-1}^{2}+\gamma \varepsilon_{t-1}^{2} I\left(\varepsilon_{t-1}<0\right)+\beta \sigma_{t-1}^{2}
$$

where $I$ denotes the indicator function. The model is also sometimes referred to as a Sign-GARCH model.

\section{Results and Discussion}

Some descriptive statistics for the monthly return of the Nigeria Stock Market are presented in Table 1.

From the results presented in Table 1, the distribution of the rate of monthly returns in Training Period is positively skewed and leptokurtic. However, for Testing Period, the standard deviation of the data is large as that in Training Period. This results, indicates the rate of returns in Testing Period is more volatile than in Training Period.

Figure 1 shows how volatile the two periods are and it shows that from 2006 to 2015 there is a great variation in financial boom in Nigeria.

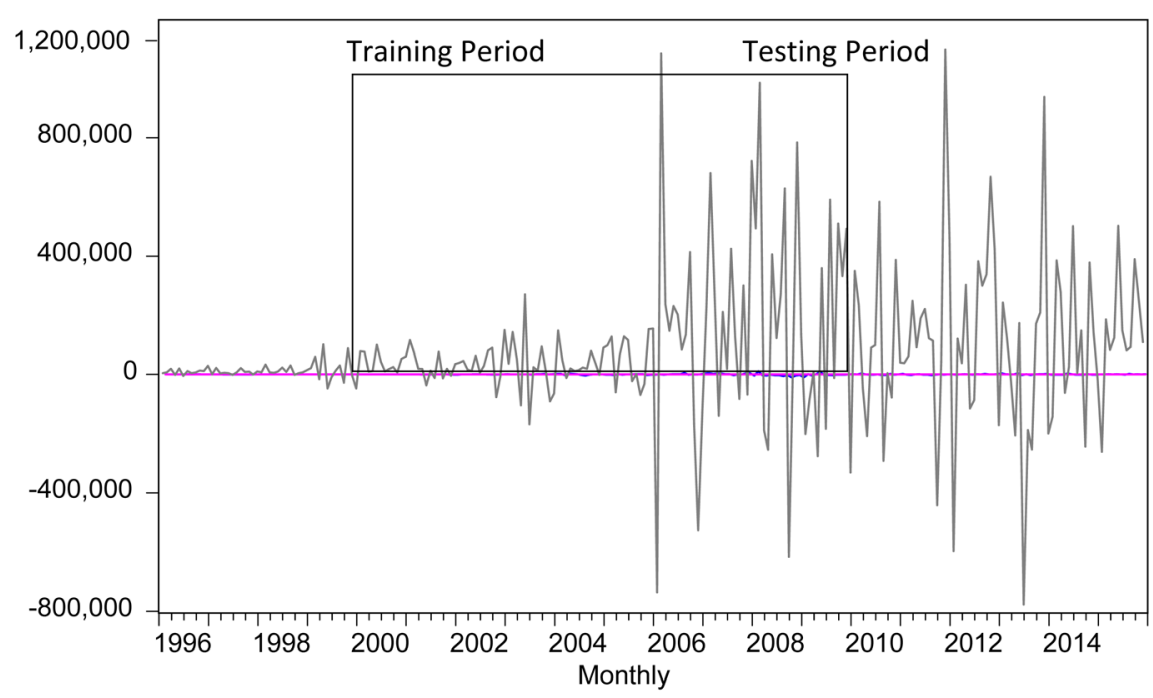

Figure 1. Monthly rate of the Nigeria stock market returns from January 1996 to December 2015.

Table 1. Summary statistics of the rate of monthly returns of the Nigeria stock market.

\begin{tabular}{ccccccc}
\hline Period & $\mathrm{N}$ & Mean & $\mathrm{Sd}$ & Variance & Skewness & Kurtosis \\
\hline Training period & 132 & -0.063207 & 0.992520 & 0.985096 & 0.274531 & 3.462173 \\
Testing period & 108 & -0.024417 & 1.006990 & 1.014029 & 0.312870 & 3.485325 \\
\hline
\end{tabular}




\subsection{Training Period}

Training Period was from January 1996 to December 2006.

Figure 2 indicates that the series is not stationary as it contains a trend components which should be remove before modeling.

From Figure 3 it shows that the trend components have been taken care.

From Figure 4 it shows that there is a strong autocorrelations function and partial autocorrelation function in the training period in Nigeria stock market returns.

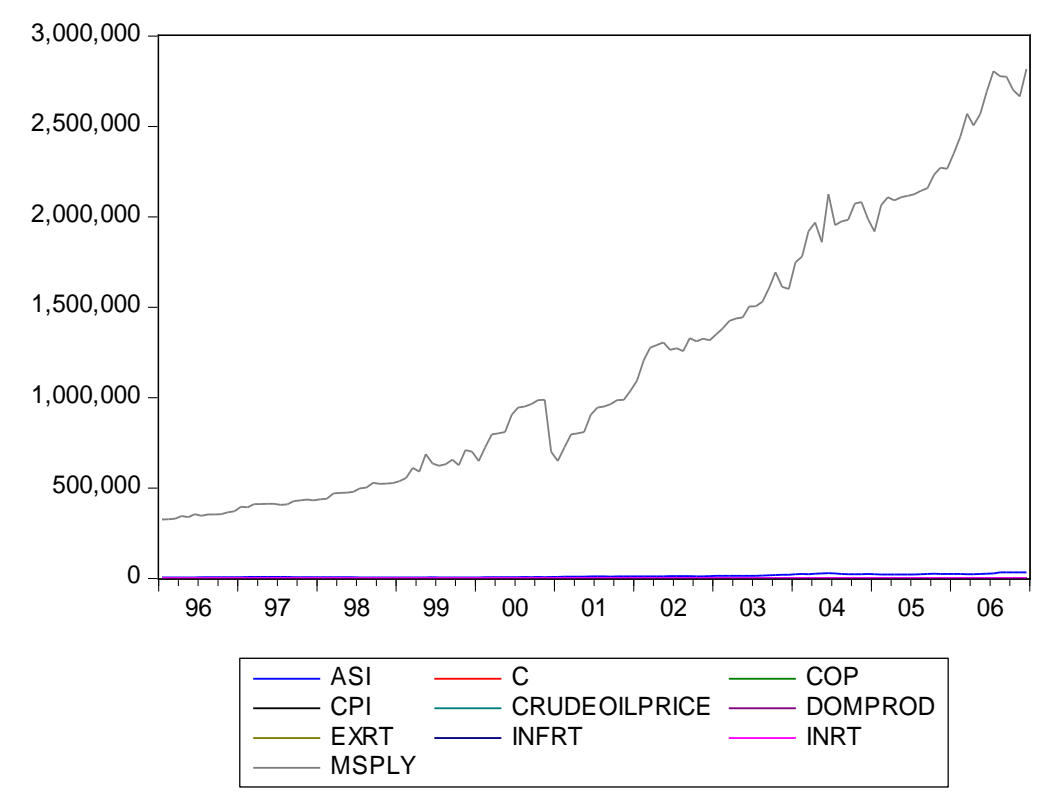

Figure 2. Graphical representation of training period on Nigeria stock market returns.

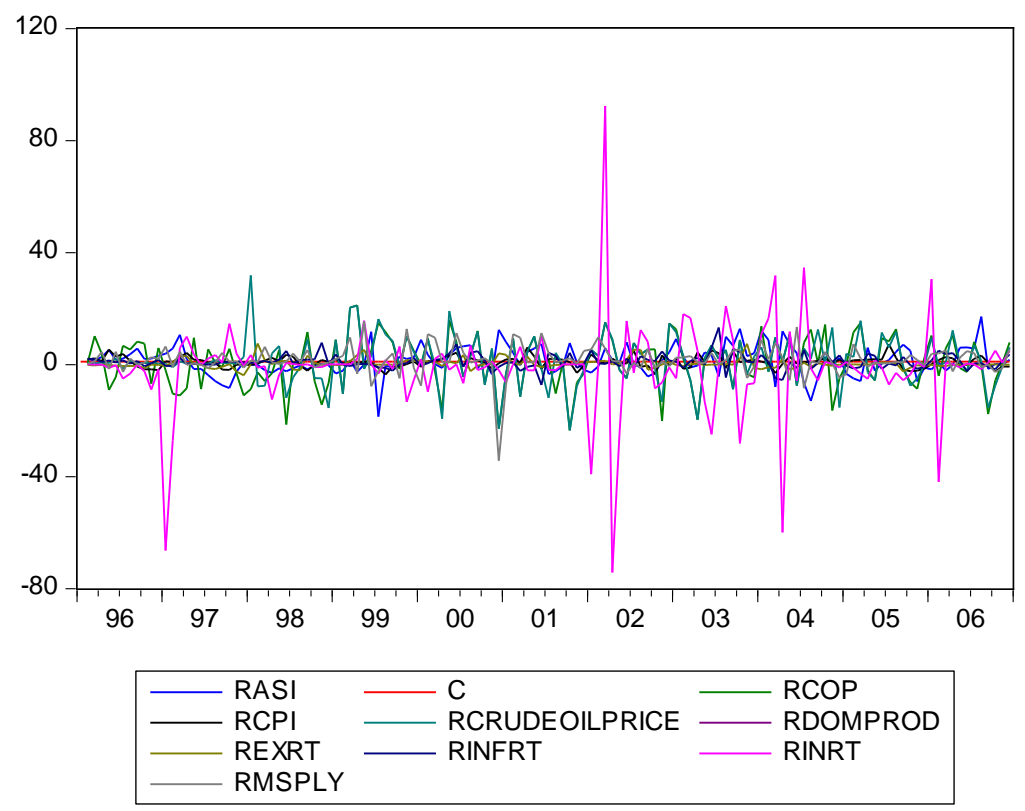

Figure 3. Graphical representation of returns logarithms of training period on Nigeria stock market. 


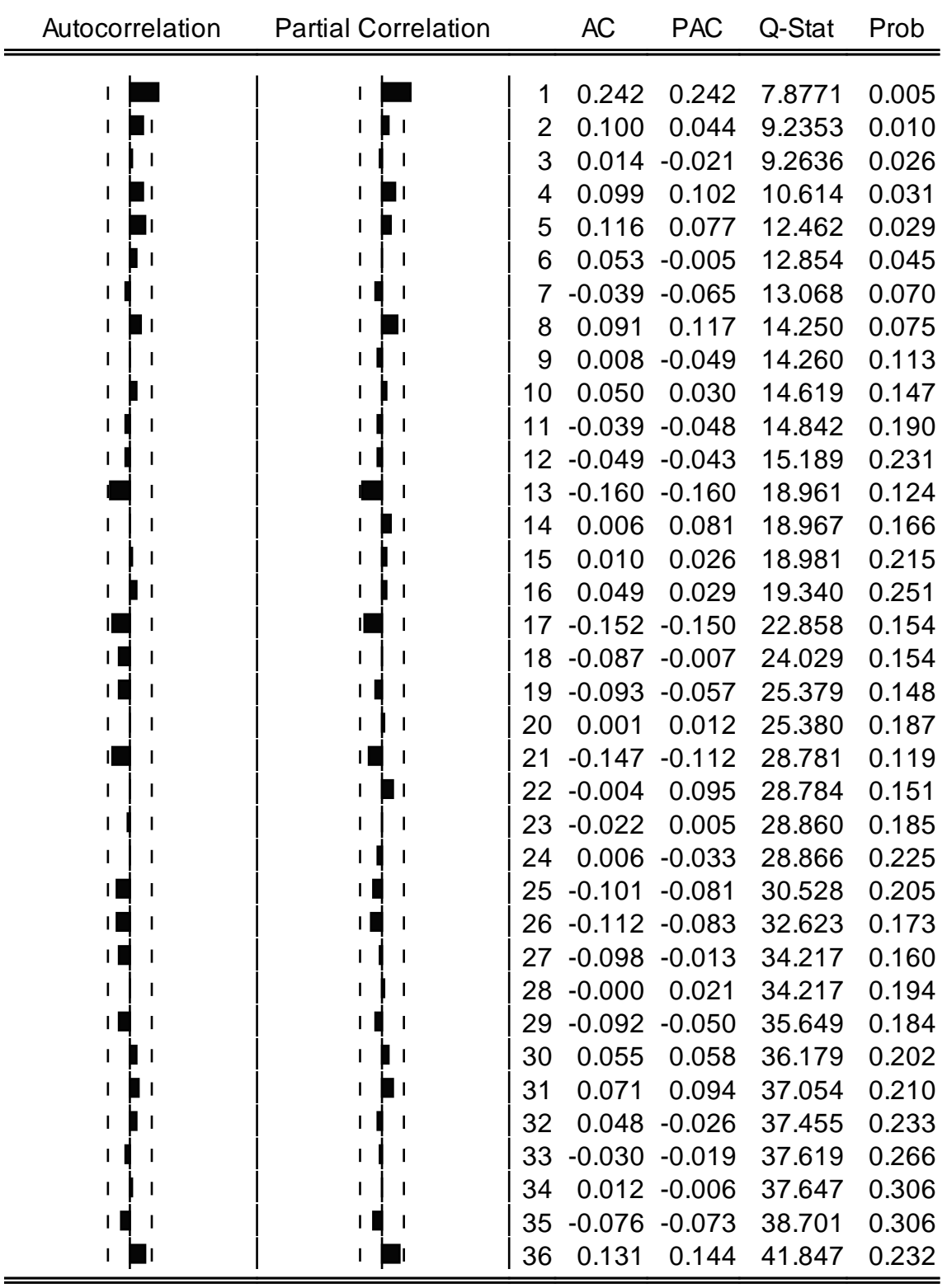

Figure 4. Correlogram test of training period on Nigeria stock market returns.

\subsubsection{Unit Root Test for the Training Period of Nigeria Stock Market Returns}

The DF-GLS statistic test the null hypothesis of unit root test against the alternative of no unit root test and the decision rule is to reject the null hypothesis is when the value of the test statistic is less than the critical value. The Ng-Perron statistic test the null hypothesis of stationary against the alternative of no stationary and the decision rule is to accept the null hypothesis when the value of the test statistic is less than the critical value. The results of the DF-GLS and Ng-Perron tests are in Table 2.

Table 2 the DF-GLS test statistic is greater than all the critical values in absolute value so the hypothesis of non-stationary is rejected. And for Ng-Perron test statistic is less than the critical value, so the hypothesis is accept. 
Table 2. Results of the unit root test for training period of the nigeria stock market returns.

\begin{tabular}{ccc}
\hline Critical Value & DF-GLS Test Statistics: -8.831925 & Ng-Perron Test Statistics: 0.40208 \\
\hline $1 \%$ & -2.582872 & 1.78000 \\
$5 \%$ & -1.943304 & 3.17000 \\
$10 \%$ & -1.615087 & 4.45000 \\
\hline
\end{tabular}

\subsubsection{Jarque Bera Normality Test}

To achieve the overall objective of the research, we examine the characteristics of the unconditional distribution of the training period of Nigeria stock market returns. This will enable us to explore and explain some stylized facts embedded in the financial time series. Jarque Bera normality test is used to demonstrate this and the results are given in Table 3: Note that the Jarque Bera test is a goodness of fit measure of departure from normality, based on the sample kurtosis and skewness.

From Figure 5 it indicates that the skewness is greater than zero (for the normal distribution), that is to say the distribution is negatively skewed which is an indication of a no asymmetrical series, meaning that there is a symmetrical effects in these models which is another stylize fact of financial time series. The kurtosis is also greater than 3 (the kurtosis of a normal distribution). Jarque Bera normality test statistic shown that, neither returns series has a normal distribution.

From the results obtained in Table 3 showed the results of the three criteria values which are Log Likelihood ( $\log \mathrm{L}$ ), Schwarzs Bayesian Criterion (SBC) and the Akaike Information Criterion (AIC) values of the ARCH and GARCH models that is used in choosing the best fit model from Training period of Nigeria stock market returns.

The results obtained in Table 4 shows the parameter estimates and the values of $t$-ratio. All parameter estimates, with the exception of $\alpha_{1}$ for GJR-GARCH $(1,1), \beta_{1}$ for GARCH $(1,1)$ and $\operatorname{EGARCH}(1,1), \alpha_{2}$ for ARCH $(2), \beta_{2}$ for CGARCH $(1,1)$ and GARCH $(2,2)$ and $\theta$ for CGARCH $(1,1)$ are significant at $5 \%$ level.

\subsection{Testing Period}

Testing Period was from January 2007 to December 2015.

Figure 6 indicates that the series is not stationary as it contains a trend components which should be remove before modeling.

Figure 7 shows that the trend component has been taken care of.

\subsubsection{Correlogram Test of Training Period on Nigeria Stock Market Returns}

Having discovered that the Nigeria Stock Market returns series could be modeled as ARCH and GARCH, the next is to examine the ACF and PACF to see the degree of correlation in the data point of the series.

Figure 8 shows that there is a strong autocorrelations function and partial autocorrelation function in the testing period in Nigeria stock market returns. 


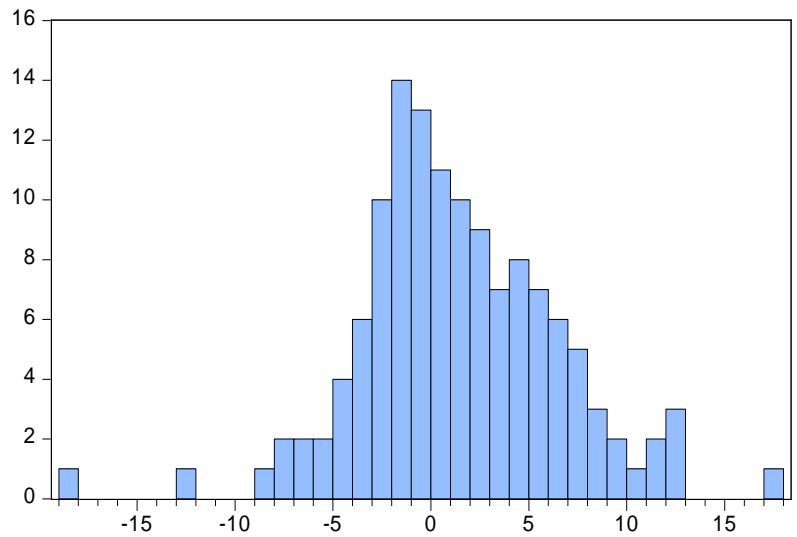

Series: RTASI

Sample 1996M01 2006M12

Observations 131

Mean $\quad 1.424525$

Median $\quad 0.765544$

Maximum $\quad 17.14970$

Minimum $\quad-18.57769$

Std. Dev. $\quad 5.155811$

Skewness $\quad-0.104501$

Kurtosis $\quad 4.571974$

Jarque-Bera $\quad 13.72654$

Probability $\quad 0.001045$

Figure 5. Jarque Bera normality test of training period of Nigeria stock market returns.

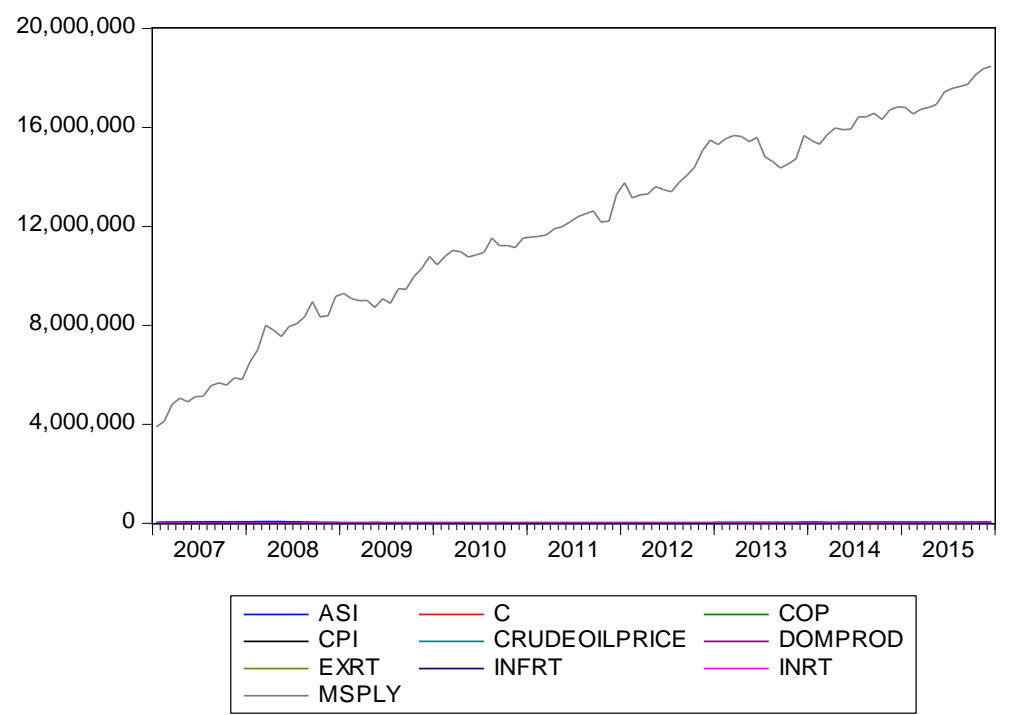

Figure 6. Graphical representation of testing period on Nigeria stock market returns.

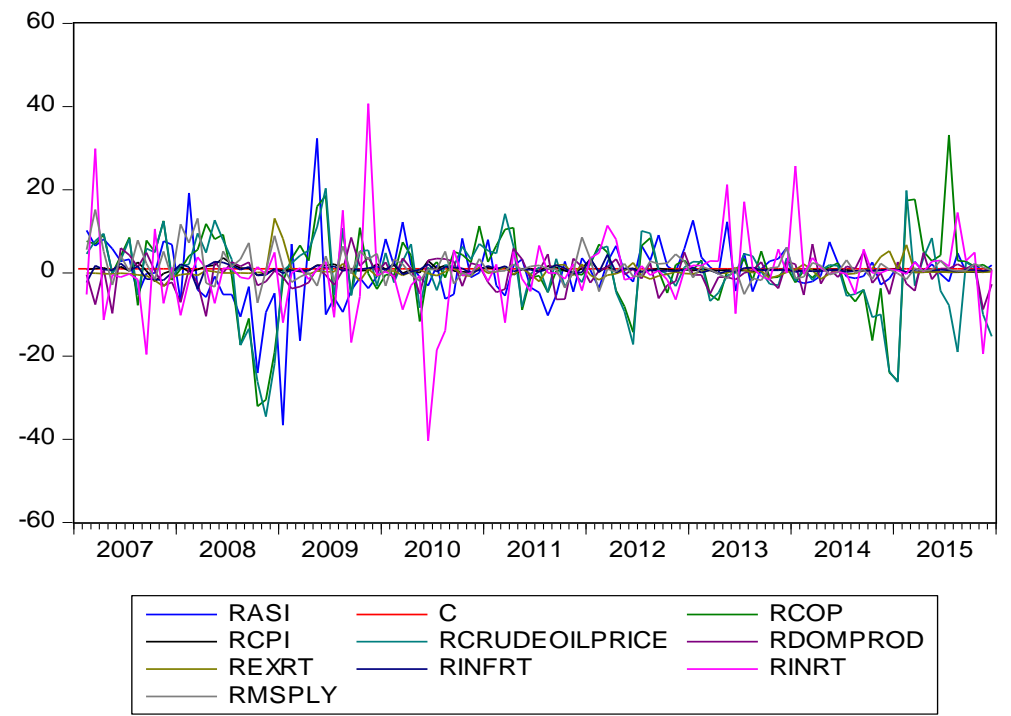

Figure 7. Graphical representation of returns logarithms of testing period on Nigeria stock market. 


\begin{tabular}{|c|c|c|c|c|c|c|}
\hline Autocorrelation & Partial Correlation & & $A C$ & PAC & Q-Stat & Prob \\
\hline I & I & 1 & 0.070 & 0.070 & 0.5369 & 0.464 \\
\hline । & 1 & 2 & 0.172 & 0.168 & 3.8393 & 0.147 \\
\hline I & 1 & 3 & 0.219 & 0.204 & 9.2222 & 0.026 \\
\hline 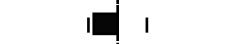 & $\mathbf{E}$ & 4 & -0.159 & -0.221 & 12.073 & 0.017 \\
\hline I & $\mathbf{I}$ & 5 & 0.180 & 0.145 & 15.762 & 0.008 \\
\hline I & $\mathbf{I}$ & 6 & -0.031 & -0.039 & 15.872 & 0.014 \\
\hline 1 & 1 & 7 & 0.007 & 0.046 & 15.877 & 0.026 \\
\hline I & 1 & 8 & 0.028 & -0.079 & 15.972 & 0.043 \\
\hline I & I & 9 & 0.078 & 0.180 & 16.701 & 0.054 \\
\hline I & 1 & 10 & 0.145 & 0.086 & 19.218 & 0.038 \\
\hline II & 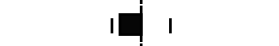 & 11 & -0.090 & -0.142 & 20.202 & 0.043 \\
\hline I & I & 12 & 0.070 & -0.012 & 20.797 & 0.053 \\
\hline 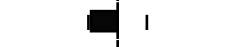 & 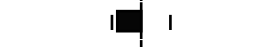 & 13 & -0.176 & -0.168 & 24.628 & 0.026 \\
\hline 1 & 1 & 14 & -0.074 & 0.011 & 25.317 & 0.032 \\
\hline I & 1 & 15 & 0.032 & -0.006 & 25.445 & 0.044 \\
\hline 1 & II & 16 & -0.203 & -0.075 & 30.744 & 0.015 \\
\hline I & 1 & 17 & 0.001 & -0.053 & 30.744 & 0.021 \\
\hline 1 & 1 & 18 & -0.141 & -0.089 & 33.344 & 0.015 \\
\hline I & I & 19 & -0.107 & -0.053 & 34.850 & 0.015 \\
\hline 1 & 1 & 20 & -0.025 & -0.043 & 34.933 & 0.020 \\
\hline I & 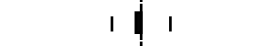 & 21 & -0.154 & -0.041 & 38.129 & 0.012 \\
\hline I & 1 & 22 & -0.068 & -0.050 & 38.772 & 0.015 \\
\hline 1 & 1 & 23 & -0.019 & 0.118 & 38.821 & 0.021 \\
\hline I & 1 & 24 & 0.042 & 0.075 & 39.072 & 0.027 \\
\hline 1 & 1 & 25 & 0.086 & 0.107 & 40.117 & 0.028 \\
\hline 1 & 1 & 26 & 0.028 & -0.010 & 40.234 & 0.037 \\
\hline I & II & 27 & -0.025 & -0.074 & 40.323 & 0.048 \\
\hline I & I I & 28 & -0.080 & -0.068 & 41.280 & 0.051 \\
\hline I & I & 29 & 0.038 & 0.051 & 41.500 & 0.062 \\
\hline I & 1 & 30 & -0.018 & 0.022 & 41.547 & 0.078 \\
\hline I & 1 & 31 & 0.052 & 0.084 & 41.967 & 0.090 \\
\hline 1 & 1 & 32 & 0.104 & 0.043 & 43.643 & 0.082 \\
\hline I & I & 33 & -0.042 & -0.107 & 43.918 & 0.097 \\
\hline 1 & 1 & 34 & 0.118 & -0.026 & 46.132 & 0.080 \\
\hline I & 1 & 35 & 0.140 & 0.093 & 49.285 & 0.055 \\
\hline 1 & I & 36 & 0.045 & 0.075 & 49.612 & 0.065 \\
\hline
\end{tabular}

Figure 8. Correlogram test of testing period on Nigeria stock market returns.

Table 3. The criteria value of the ARCH and GARCH models of training period on Nigeria stock market returns.

\begin{tabular}{cccc}
\hline Model & LOGL & SBC & AIC \\
\hline ARCH $(1)$ & -386.6639 & 6.312633 & 6.071205 \\
ARCH $(2)$ & -386.1990 & 6.342750 & 6.079373 \\
PARCH $(1,1)$ & -384.5735 & 6.466795 & 6.115626 \\
GARCH $(1,1)$ & -386.2125 & 6.342958 & 6.079581 \\
GARCH $(1,2)$ & -382.5851 & 6.324792 & 6.039467 \\
GARCH $(2,1)$ & -380.4210 & 6.291753 & 6.006428 \\
EGARCH $(1,1)$ & -380.1429 & 6.287507 & 6.002182 \\
GJR-GARCH $(1,1)$ & -389.1248 & 6.424635 & 6.139310 \\
CGARCH $(1,1)$ & -389.5262 & 6.579624 & 6.206507 \\
GARCH-M $(1,1)$ & -382.2043 & 6.356194 & 6.048921 \\
GARCH $(2,2)$ & -382.1420 & 6.355243 & 6.047970 \\
\hline
\end{tabular}


Table 4. Estimation results of the monthly rate of returns for training period.

\begin{tabular}{|c|c|c|c|c|c|c|c|c|c|c|c|c|c|c|}
\hline MODEL & $\omega \times 10^{-5}$ & t-ratio & $\alpha_{1}$ & t-ratio & $\beta_{1}$ & t-ratio & $\alpha_{2}$ & t-ratio & $\beta_{2}$ & t-ratio & $\delta$ & t-ratio & $\theta$ & t-ratio \\
\hline $\mathrm{ARCH}(1)$ & 10.023 & 3.29 & 0.82 & 3.12 & & & & & & & & & & \\
\hline $\mathrm{ARCH}(2)$ & 10.605 & 3.14 & 0.78 & 3.07 & & & -0.02 & -0.42 & & & & & & \\
\hline PARCH $(1,1)$ & 2.3729 & 1.21 & 0.32 & 2.13 & 0.36 & 1.81 & 0.08 & 0.92 & & & 0.81 & 0.56 & & \\
\hline GARCH $(1,1)$ & 10.891 & 2.89 & 0.79 & 3.07 & -0.03 & -0.41 & & & & & & & & \\
\hline GARCH $(1,2)$ & 10.186 & 2.39 & 0.61 & 2.47 & -0.14 & -1.51 & 0.23 & 2.19 & & & & & & \\
\hline GARCH $(2,1)$ & 1.8803 & 2.85 & 0.77 & 3.44 & -0.74 & -3.68 & & & 0.91 & 22.8 & & & & \\
\hline EGARCH $(1,1)$ & 3.0994 & 4.80 & 1.17 & 4.45 & 0.01 & 0.05 & & & & & & & -0.37 & -2.29 \\
\hline GJRGARCH $(1,1)$ & 11.098 & 0.86 & -0.01 & -0.79 & -0.08 & -2.50 & & & & & 0.59 & 1.19 & & \\
\hline CGARCH $(1,1)$ & 23.121 & 5.11 & 0.02 & 0.02 & 0.07 & 0.02 & 0.05 & 0.02 & -0.03 & -0.36 & & & 0.00 & 0.00 \\
\hline GARCH-M $(1,1)$ & 15.346 & 3.96 & 0.35 & 2.06 & 0.39 & 1.07 & & & & & -0.12 & -1.12 & & \\
\hline GARCH $(2,2)$ & 3.8942 & 2.86 & 0.88 & 3.37 & -0.67 & -4.04 & 0.74 & 4.09 & -0.03 & -1.01 & & & & \\
\hline
\end{tabular}

\subsubsection{Unit Root Test for the Testing Period of Nigeria Stock Market Returns}

The DF-GLS statistic test the null hypothesis of unit root against the alternative of no unit root and the decision rule is to reject the null hypothesis is when the value of the test statistic is less than the critical value. The Ng-Perron statistic test the null hypothesis of stationary against the alternative of no stationary and the decision rule is to accept the null hypothesis when the value of the test statistic is less than the critical value. The results of the DF-GLS and Ng-Perron tests are in Table 5.

From Table 5 DF-GLS test statistic is greater than all the critical values in absolute value so the hypothesis of non-stationary is rejected. And for Ng-Perron test statistic is less than the critical value, so the hypothesis is accept.

\subsubsection{Jarque Bera Normality Test}

To achieve the overall objective of the research, we examine the characteristics of the unconditional distribution of the training period of Nigeria stock market returns. This will enable us to explore and explain some stylized facts embedded in the financial time series. Tarque Bera normality test is used to demonstrate this and the results are given in Figure 9: Note that the Jarque Bera test is a goodness of fit measure of departure from normality, based on the sample kurtosis and skewness.

Figure 9 indicate that the skewness is greater than zero (for the normal distribution), that is to say the distribution is negatively skewed which is an indication of a no asymmetrical series, meaning that there is a symmetrical effects in these models which is another stylize fact of financial time series. The kurtosis is also greater than 3 (the kurtosis of a normal distribution). Recall that; relatively large kurtosis suggests that the distribution of the Nigeria stock market returns series is leptokurtic which is another stylize fact. Thereafter, Jarque Bera normality test statistic indicates that, neither returns series has a normal distribution.

Table 6 results shown that the result of the three criteria values which are Log Likelihood (Log L), Schwarzs Bayesian Criterion (SBC) and the Akaike Informa- 


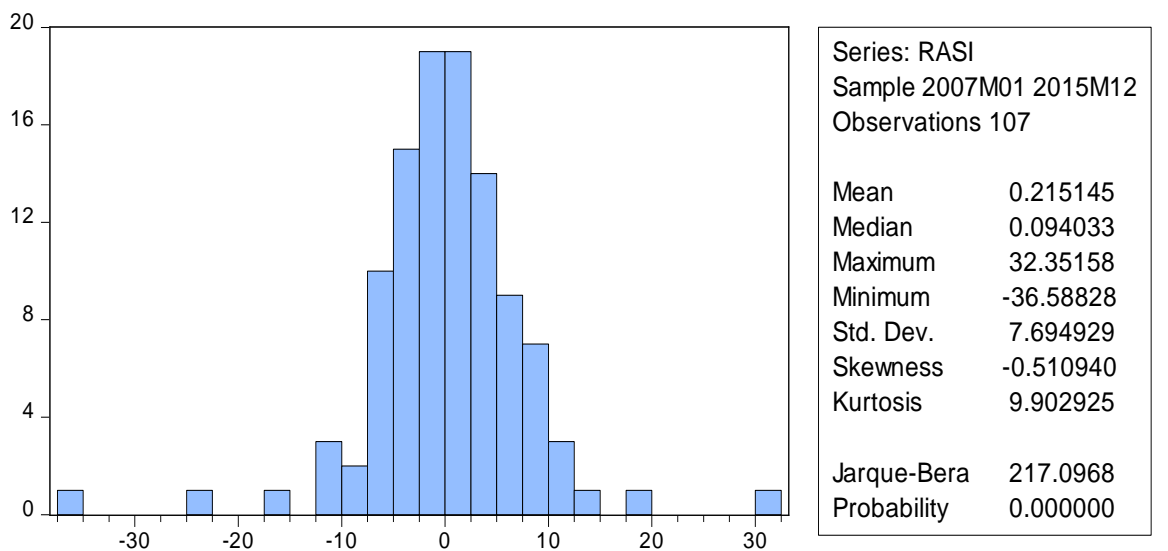

Figure 9. Jarque Bera normality test of training period of Nigeria stock market returns.

Table 5. Results of the unit root test for testing period of the Nigeria stock market returns.

\begin{tabular}{ccc}
\hline Critical Value & DF-GLS Test Statistics: -2.245094 & Ng-Perron Test Statistics: 3.11222 \\
\hline $1 \%$ & -2.587387 & 1.78000 \\
$5 \%$ & -1.943943 & 3.17000 \\
$10 \%$ & -1.614694 & 4.45000 \\
\hline
\end{tabular}

Table 6. The criteria values of the ARCH and GARCH models of testing period on nigeria stock market returns.

\begin{tabular}{cccc}
\hline Model & LOGL & SBC & AIC \\
\hline ARCH $(1)$ & -354.5865 & 7.108170 & 6.833393 \\
ARCH $(2)$ & -339.1416 & 6.863150 & 6.563394 \\
PARCH $(1,1)$ & -329.9103 & 6.821617 & 6.446921 \\
GARCH $(1,1)$ & -335.0621 & 6.786899 & 6.487142 \\
GARCH $(1,2)$ & -329.8165 & 6.732520 & 6.407784 \\
GARCH $(2,1)$ & -331.6776 & 6.767307 & 6.442571 \\
EGARCH $(1,1)$ & -351.1336 & 7.130971 & 6.806235 \\
GJR-GARCH $(1,1)$ & -333.9890 & 6.810512 & 6.485776 \\
CGARCH $(1,1)$ & -335.1591 & 7.007068 & 6.582413 \\
GARCH-M $(1,1)$ & -332.9424 & 6.834621 & 6.484905 \\
GARCH $(2,2)$ & -330.8776 & 6.796026 & 6.446310 \\
\hline
\end{tabular}

tion Criterion (AIC) values of the ARCH and GARCH models that is used in choosing the best fit model from Testing period of Nigeria stock market returns.

The results obtained in Table 7 shows the parameter estimates and the values of t-ratio. All parameter estimates, with the exception of $\alpha_{1}$ for GARCH-M $(1,1)$, $\beta_{1}$ for GARCH $(2,2), \alpha_{2}$ for CGARCH $(1,1)$, and $\omega$ for GARCH $(1,1)$ and GJR-GARCH $(1,1)$ are significant at $5 \%$ level. 
Table 7. Estimation results of the monthly rate of returns for Testing period.

\begin{tabular}{|c|c|c|c|c|c|c|c|c|c|c|c|c|c|c|}
\hline MODEL & $\omega \times 10^{-5}$ & t-ratio & $\alpha_{1}$ & t-ratio & $\beta_{1}$ & t-ratio & $\alpha_{2}$ & t-ratio & $\beta_{2}$ & t-ratio & $\delta$ & t-ratio & $\theta$ & t-ratio \\
\hline $\mathrm{ARCH}(1)$ & 20.5 & 3.40 & 0.99 & 2.84 & & & & & & & & & & \\
\hline $\mathrm{ARCH}(2)$ & 12.6 & 2.97 & 0.07 & 0.46 & & & 0.85 & 3.58 & & & & & & \\
\hline PARCH $(1,1)$ & 0.41 & 0.14 & 0.29 & 0.95 & 0.31 & 2.98 & 0.45 & 1.75 & 5.63 & 1.39 & & & & \\
\hline GARCH $(1,1)$ & -0.03 & -0.06 & 0.39 & 2.29 & 0.68 & 5.88 & & & & & & & & \\
\hline GARCH $(1,2)$ & -0.59 & -4.09 & 0.41 & 2.36 & 0.33 & 1.01 & 0.34 & 1.22 & & & & & & \\
\hline GARCH $(2,1)$ & -0.39 & -1.71 & 0.45 & 2.03 & -0.19 & -1.04 & & & 0.79 & 9.63 & & & & \\
\hline EGARCH $(1,1)$ & 4.56 & 5.66 & 0.13 & 0.48 & 0.54 & 3.29 & & & & & & & -0.25 & -1.20 \\
\hline GJRGARCH $(1,1)$ & 0.01 & 0.02 & 0.24 & 1.90 & 0.26 & 1.43 & & & & & 0.69 & 6.89 & & \\
\hline CGARCH $(1,1)$ & 42.2 & 0.82 & 0.89 & 7.64 & 0.16 & 0.32 & -0.02 & -0.04 & 0.17 & 0.78 & & & 0.78 & 1.46 \\
\hline GARCH-M $(1,1)$ & 1.89 & 0.75 & -0.02 & -0.18 & 0.67 & 2.16 & & & & & 0.73 & 5.33 & & \\
\hline GARCH $(2,2)$ & -0.57 & -1.34 & 0.42 & 1.87 & -0.04 & -0.13 & 0.42 & 0.62 & 0.28 & 0.54 & & & & \\
\hline
\end{tabular}

\section{Conclusion}

In this study the method for selecting the best model from a set of competing GARCH models for fitting the Nigeria Stock Market Return series was used. The method identified exactly the best and worst fit models as for the two periods. However, as a whole, the models occupying the intermediate positions differ in the method. The results obtained from the Log Likelihood (Log L), Schwarzs Bayesian Criterion (SBC) and the Akaike Information Criterion (AIC) values found out that the models identified by the method were not the same for the two periods i.e. for Training period were CGARCH $(1,1)$ and EGARCH $(1,1)$ while for Testing period were ARCH (1) and GARCH $(2,1)$. The two extreme classes of models are identified to represent the best and the worst groups respectively. The overall effect of this will tend to increase the volatility of the market returns. Another advantage is that the method can help models to be classified in to several distinct groups ordered in such a way that each group is made up of models with about the same level of fitting ability. The two extreme classes of models are identified to represent the best and the worst groups respectively.

\section{Contributions to Knowledge}

Based on our findings, this research has contributed to the knowledge in the following directions:

1) We find out that the result of the criteria ( $\log$ Likelihood $(\log \mathrm{L})$, Schwarzs Bayesian Criterion (SBC) and the Akaike Information Criterion (AIC)) are use to identify the best fit model.

2) And the parameter estimate are being classified in to different groups and with those that have exceptional.

\section{Limitation of This Paper}

It is our suggestion that for future researchers can applied principal component 
analysis in testing the best fit model among the GARCH model.

\section{References}

[1] Engle, R.F. (1982) Autoregressive Conditional Heteroscedasticity with Estimates of Variance of United Kingdom Inflation. Econometrica, 50, 987-1008.

https://doi.org/10.2307/1912773

[2] Bollerslev, T. (1986) Generalized Autoregressive Conditional Heteroscedasticity. Journal of Econometrics, 31, 307-327. https://doi.org/10.1016/0304-4076(86)90063-1

[3] Chou, R.Y. (1988) Volatility Persistence and Stock Valuations: Some Empirical Evidence Using GARCH. Journal of Applied Economics, 3, 279-294. https://doi.org/10.1002/jae.3950030404

[4] Nelson, D.B. (1991) Conditional Heteroscedasticity in Asset Returns: A New Approach. Econometrics, 52, 347-70.

[5] Bollerslev, T., Chou, R. and Kroner, F. (1992) ARCH Modeling in Finance: A Review of the Theory and Empirical Evidence. Journal of Econometrics, 52, 5-59. https://doi.org/10.1016/0304-4076(92)90064-X

[6] Engle, R.F. and Patton, A.J. (2001) What Good Is a Volatility Model? Quantitative Finance, 1, 237-245. https://doi.org/10.1088/1469-7688/1/2/305

[7] Engle, R.F., Ng, V.K. and Rothschild, M. (1990) Asset Pricing with a Factor-ARCH Covariance Structure: Empirical Estimates for Treasury Bills. Journal of Econometrics, 45, 213-238.

[8] Engle, R.F. (2000) Dynamic Conditional Correlation: A Simple Class of Multivariate GARCH Models. http://pages.stern.nyu.edu/ rengle/dccfinal.pdf

[9] Lee, C.F., Chen, G.M. and Rui, O.M. (2001) Stock Returns and Volatility on China Stock Markets. Journal of Financial Research, 24, 523-543. https://doi.org/10.1111/j.1475-6803.2001.tb00829.x

[10] Balaban, E., Bayar, A. and Faff, R. (2005) Forecasting Stock Market Volatility: Further International Evidence. ASAC, Quebec, Canada.

[11] Tudor, C. (2008) An Empirical Study on Risk-Return Tradeoff Using GARCH-Class Models: Evidence from Bucharest Stock Exchange. International Conference on Business and Economy ICBE Constanta - Romania, 6-8 November 2008.

[12] Ebeid, S.T. and Bedeir, G.B. (2004) Volatility Modelling and Forecasting of the Egyptian Stock Market Volatility Index using ARCH Models. Working Paper, 1-15.

[13] Pindyck, R. (1984) Risk, Inflation and the Stock Market. American Economic Review, 74, 335-351.

[14] Whitelaw, R. (1994) Time Variations and Covariations in the Expectation and Volatility of Stock Market Returns. Journal of Finance, 49, 515-541. https://doi.org/10.1111/j.1540-6261.1994.tb05150.x

[15] Koutmos, G.F. (1999) Asymmetric Price and Volatility Adjustments in Emerging Asian Stock Market. Journal of Business Finance \& Accounting, 26, 83-101. https://doi.org/10.1111/1468-5957.00249

[16] Koutmos, G. and Saidi, R. (1995) The Leverage Effect in Individual Stocks and the Debt to Equity Ratio. Journal of Business Finance and Accounting, 22, 1063-1075. https://doi.org/10.1111/j.1468-5957.1995.tb00894.x

[17] Ogum, G., Beer, F. and Nouyrigat, G. (2005) Emerging Equity Market Volatility: An Empirical Investigation of Markets in Kenya and Nigeria. Journal of African Busi- 
ness, 6, 139-154. https://doi.org/10.1300/J156v06n01_08

[18] Amaefula, C.G. and Asare, B.K. (2014) The Impacts of Inflation Dynamics and Global Financial Crises on Stock Market Returns and Volatility. Evidence from $\mathrm{Ni}$ geria, Asian Economic and Financial Review, 4, 641-650.

[19] Olowe, R.A. (2009) Modelling Naira/Dollar Exchange Rate Volatility: Evidence from GARCH and Asymmetric Models. International Review of Business Research Papers, 5, 377-398.

[20] Franses, P.H. and Van Dijk, R. (1996) Forecasting Stock Market Volatility Using (Non-Linear) Garch Models. Journal of Forecasting, 15, 229-235. https://doi.org/10.1002/(SICI)1099-131X(199604)15:3<229::AID-FOR620>3.0.CO;2 $\underline{-3}$

[21] Choo, W.C., Ahmad, M.I. and Abdullah, M.Y. (1999) Performance of GARCH Models in Forecasting Stock Market Volatility. Journal of Forecasting, 18, 333-334. https://doi.org/10.1002/(SICI)1099-131X(199909)18:5<333::AID-FOR742>3.0.CO;2 $-\mathrm{K}$

[22] Gokcan, S. (2000) Forecasting Volatility of Emerging Stock Markets: Linear versus Non-Linear GARCH Models. Journal of Forecasting, 19, 499-504. https://doi.org/10.1002/1099-131X(200011)19:6<499::AID-FOR745>3.0.CO;2-P

[23] Yaya, O.S. (2013) Nigerian Stock Index: A Search for Optimal GARCH. Central Bank of Nigeria Journal of Applied Statistics, 4, 69-85.

[24] Ding, Z. and Engle, R.F. (2001) Large Scale Conditional Covariance Matrix Modeling, Estimation and Testing. Academia Economic Papers, 29, 157-184.

[25] Ding, Z., Engle, R.F. and Granger, C.W.J. (1993) A Long Memory Properties of Stock Market Returns and a New Model. Journal of Empirical Finance, 1, 83-106. https://doi.org/10.1016/0927-5398(93)90006-D

[26] Floros, C. (2008) Modelling Volatility Using GARCH Models: Evidence from Egypt and Israel. Middle Eastern Finance and Economics, 2, 31-41.

[27] Ocran, M. and Biekets, N. (2007) Forecasting Volatility in Sub-Saharan Africa's Commodity Markets. Investment Management and Financial Innovations, 4, 91-102.

[28] Glosten, L.R., Jagannathanand, D. and Runkle, C. (1993) On the Relation between the expected value and the Volatility of the Nominal Excess Return on Stocks. Journal of Finance, 48, 1779-1801. 